\title{
Preoperative mean corpuscular hemoglobin affecting long-term outcomes of hepatectomized patients with hepatocellular carcinoma
}

\author{
PINZHU HUANG ${ }^{1,2^{*}}$, CHUNHONG LIU ${ }^{3 *}$, BINKUI LI $^{1}$, YUN ZHENG $^{1}$, \\ RUHAI ZOU ${ }^{1}$, JUN HUANG $^{1,2}$, ZEMIN HU $^{3}$ and YUNFEI YUAN ${ }^{1}$ \\ ${ }^{1}$ State Key Laboratory of Oncology in South China, Department of Hepatobiliary Oncology, \\ Sun Yat-Sen University Cancer Center, Guangzhou, Guangdong 510060; ${ }^{2}$ Gastrointestinal Institute \\ and Department of Colorectal Surgery, The Sixth Affiliated Hospital, Sun Yat-Sen University, Guangzhou, \\ Guangdong 510655; ${ }^{3}$ Department of Hepatobiliary Surgery, Affiliated Zhongshan Hospital, \\ Sun Yat-Sen University, Zhongshan, Guangdong 528403, P.R. China
}

Received May 7,2015; Accepted November 19, 2015

DOI: $10.3892 / \mathrm{mco} .2015 .705$

\begin{abstract}
Pretreatment anemia has been reported to be associated with survival in several solid tumor types. In terms of survival, only limited data on the hemoglobin (HGB) level in hepatocellular carcinoma (HCC) have been published and no data on mean corpuscular hemoglobin $(\mathrm{MCH})$ level in $\mathrm{HCC}$ is available. The present study sought to examine the role of $\mathrm{HGB}$ and $\mathrm{MCH}$ levels in predicting long-term survival of patients with HCC who undergo resection. A retrospective study of 399 consecutive patients (1987-1994) who underwent hepatic resection for HCC in Sun Yat-Sen University Cancer Centre was performed. Serum HGB and $\mathrm{MCH}$ levels were examined preoperatively, and their prognostic capabilities were evaluated by Cox's proportional hazard model. Among the whole cohort, the HGB level appeared to be positively correlated with the MCH level $(\mathrm{P}<0.001)$. Survival analysis revealed that low levels of $\mathrm{HGB}(\mathrm{P}=0.007)$ and $\mathrm{MCH}(\mathrm{P}<0.001)$ were correlated with shorter overall survival (OS). Multivariate analysis revealed that $\mathrm{MCH}$ level was independently associated with OS $(\mathrm{P}<0.001)$, however, not HGB $(\mathrm{P}=0.278)$. In addi-
\end{abstract}

Correspondence to: Dr Yunfei Yuan, State Key Laboratory of Oncology in South China, Department of Hepatobiliary Oncology, Sun Yat-Sen University Cancer Center, 651 Dongfeng East Road, Guangzhou, Guangdong 510060, P.R. China

E-mail: yuanyf@mail.sysu.edu.cn

*Contributed equally

Abbreviations: AFP, $\alpha$-fetoprotein; $\mathrm{HGB}$, hemoglobin; $\mathrm{MCH}$, mean corpuscular hemoglobin; HBsAg, hepatitis B surface antigen; TNM, tumor-node-metastasis; HCC, hepatocellular carcinoma; OS, overall survival

Key words: hemoglobin, mean corpuscular hemoglobin, hepatocellular carcinoma, prognosis tion, 129 patients with large $\mathrm{HCC}(\geq 10 \mathrm{~cm})$ tended to have a poorer OS $(\mathrm{P}<0.001)$ when compared with patients with smaller HCC. On subanalysis of patients with large $\mathrm{HCC}, \mathrm{MCH}$ level also retained its stratified significance $(\mathrm{P}=0.001)$. Along with common clinicopathological variables, these results suggested that $\mathrm{MCH}$, however, not $\mathrm{HGB}$, may be useful in assessing prognosis for patients with HCC who undergo hepatectomy, particularly in identifying patients with large HCC who are most likely benefit from resection.

\section{Introduction}

Hepatocellular carcinoma (HCC) is one of the most prevalent tumor types worldwide (1). In Asia, resection of HCC remains the predominant treatment for potentially curable diseases. Even in patients with huge $\mathrm{HCC}$, it is possible to obtain long-term survival for the well-selected subsets of patients following surgical resection (2). However, prognosis of patients with HCC who undergo resection differs substantially and large variation is predominantly unexplained. Therefore, the risk factors for postoperative survival prediction in patients with HCC have been intensively studied $(3,4)$. Nevertheless, the clinical outcomes for patients with HCC with identical clinicopathological characteristics are heterogeneous (5). Owing to the limitations of current staging systems and advances in the understanding of the biology of HCC, molecular alterations can complement clinical variables in staging systems and guide therapeutic decision-making (6). Unfortunately, evaluating molecular markers requires extra time and effort, as well as increased cost. Therefore, routine laboratory assessments, including $\gamma$-glutamyl transpeptidase (GGT) (7), monocyte count (8), platelet count (9) and neutrophil-to-lymphocyte ratio (10) have been developed to be predictive factors for survival in HCC.

Hypoxia appears to be an influencing factor for numerous cancer types, and anemia has been suggested to be associated with tumor hypoxia (11). Previously, evidence has indicated that anemia is correlated with poor clinical 
Table I. HGB and MCH levels in relation to the clinicopathalogical variables in 399 patients with HCC.

\begin{tabular}{|c|c|c|c|c|c|c|c|}
\hline \multirow[b]{2}{*}{ Variable } & \multirow[b]{2}{*}{$\begin{array}{l}\text { No. } \\
\text { cases }\end{array}$} & \multicolumn{3}{|c|}{ HGB } & \multicolumn{3}{|c|}{$\mathrm{MCH}$} \\
\hline & & $\begin{array}{c}\leq 110 \mathrm{~g} / 1 \\
\mathrm{n}(\%) \\
(\mathrm{n}=51)\end{array}$ & $\begin{array}{c}>110 \mathrm{~g} / \mathrm{l} \\
\mathrm{n}(\%) \\
(\mathrm{n}=348)\end{array}$ & P-value & $\begin{array}{l}\leq 27 \mathrm{pg} \\
\mathrm{n}(\%) \\
(\mathrm{n}=88)\end{array}$ & $\begin{array}{c}>27 \mathrm{pg} \\
\mathrm{n}(\%) \\
(\mathrm{n}=311)\end{array}$ & P-value \\
\hline \multicolumn{8}{|l|}{ Age, years } \\
\hline$\leq 48$ & 207 & $30(14.5)$ & $177(85.5)$ & \multirow{2}{*}{0.288} & $48(23.2)$ & $159(76.8)$ & \multirow{2}{*}{0.571} \\
\hline$>48$ & 192 & $21(10.9)$ & $171(89.1)$ & & $40(20.8)$ & $152(79.2)$ & \\
\hline \multicolumn{8}{|l|}{ Gender } \\
\hline Female & 43 & $10(23.3)$ & $33(76.7)$ & \multirow{2}{*}{0.029} & $16(37.2)$ & $27(62.8)$ & \multirow{2}{*}{0.011} \\
\hline Male & 356 & $41(11.5)$ & $315(88.5)$ & & $72(20.2)$ & $284(79.8)$ & \\
\hline \multicolumn{8}{|l|}{ HBsAg } \\
\hline Negative & 80 & $13(16.3)$ & $67(83.7)$ & \multirow{2}{*}{0.299} & $24(30.0)$ & $56(70.0)$ & \multirow{2}{*}{0.055} \\
\hline Positive & 319 & $38(11.4)$ & $281(88.6)$ & & $64(20.1)$ & $255(79.9)$ & \\
\hline \multicolumn{8}{|l|}{ Cirrhosis } \\
\hline No & 86 & $10(11.6)$ & $76(88.4)$ & \multirow{2}{*}{0.717} & $23(26.7)$ & $63(73.3)$ & \multirow{2}{*}{0.236} \\
\hline Yes & 313 & $41(13.1)$ & $272(86.9)$ & & $65(20.8)$ & $248(79.2)$ & \\
\hline \multicolumn{8}{|l|}{ Tumor size } \\
\hline$<10$ & 272 & $34(12.5)$ & $238(87.5)$ & \multirow{2}{*}{0.805} & $61(22.4)$ & $211(77.6)$ & \multirow{2}{*}{0.793} \\
\hline$\geq 10$ & 127 & $17(13.4)$ & $110(86.6)$ & & $27(21.3)$ & $100(78.7)$ & \\
\hline \multicolumn{8}{|c|}{ Tumor encapsulation } \\
\hline Complete & 193 & $22(11.4)$ & $171(88.6)$ & \multirow{2}{*}{0.423} & $33(17.1)$ & $160(82.9)$ & \multirow{2}{*}{0.021} \\
\hline None & 206 & $29(14.1)$ & $177(85.9)$ & & $55(26.7)$ & $151(73.3)$ & \\
\hline \multicolumn{8}{|c|}{ Tumor number } \\
\hline Solitary & 259 & $34(13.1)$ & $225(86.9)$ & \multirow{2}{*}{0.779} & $57(22.0)$ & $202(78.0)$ & \multirow{2}{*}{0.975} \\
\hline Multiple & 140 & $17(12.1)$ & $123(87.9)$ & & $31(22.1)$ & 109 (77.9) & \\
\hline \multicolumn{8}{|c|}{ Vascular invasion } \\
\hline Absent & 326 & $42(12.9)$ & $284(87.1)$ & \multirow{2}{*}{0.898} & $75(23.0)$ & $251(77.0)$ & \multirow{2}{*}{0.333} \\
\hline Present & 73 & $9(12.3)$ & 64 (87.7) & & $13(17.8)$ & $60(82.2)$ & \\
\hline Differentia & & & & & & & \\
\hline I-II & 285 & $34(11.9)$ & $251(88.1)$ & 0.420 & $65(22.8)$ & $220(77.2)$ & 0.567 \\
\hline III-IV & 114 & $17(14.9)$ & $97(85.1)$ & & $23(20.2)$ & $91(79.8)$ & / \\
\hline TNM stage & & & & & & & \\
\hline I & 225 & $32(14.2)$ & $193(85.8)$ & 0.327 & $49(21.8)$ & $176(78.2)$ & 0.879 \\
\hline II-III & 174 & $19(10.9)$ & $155(89.1)$ & & 39 (22.4) & 135 (77.6) & 0.019 \\
\hline $\mathrm{AFP}, \mu \mathrm{g} / \mathrm{l}$ & & & & & & & \\
\hline$\leq 25$ & 127 & $21(16.5)$ & $106(83.5)$ & 0.125 & 30 (23.6) & $97(76.4)$ & 0.606 \\
\hline$>25$ & 272 & $30(11.0)$ & $242(89.0)$ & & $58(21.3)$ & $214(78.7)$ & \\
\hline
\end{tabular}

HGB, hemoglobin; MCH, mean corpuscular hemoglobin; HCC, hepatocellular carcinoma; HBsAg, hepatitis B surface antigen; TNM, tumor node metastasis; AFP, $\alpha$-fetoprotein.

prognosis in several cancer types (12-15). In addition, in $\mathrm{HCC}$, a previous report demonstrated the prognostic impact of hemoglobin (HGB) levels prior to treatment (16). The mean corpuscular hemoglobin $(\mathrm{MCH})$, which refers to a measurement of the average HGB content of each red blood cell, is another anemia associated factor, which reflects iron metabolism. Abnormalities in iron metabolism are known to be crucial in cancer progression $(17,18)$. Despite this evidence, the added value of these two markers in predicting long-term overall survival (OS) for HCC remains to be elucidated. On the basis of these considerations, the present study assessed the ability of using the levels of $\mathrm{HGB}$ and $\mathrm{MCH}$ for long-term prognosis prediction of patients with HCC resection.

\section{Patients and methods}

Study population. All patients $(\mathrm{n}=445)$ with $\mathrm{HCC}$ between January 1987 and December 1994 underwent hepatic resection 
A

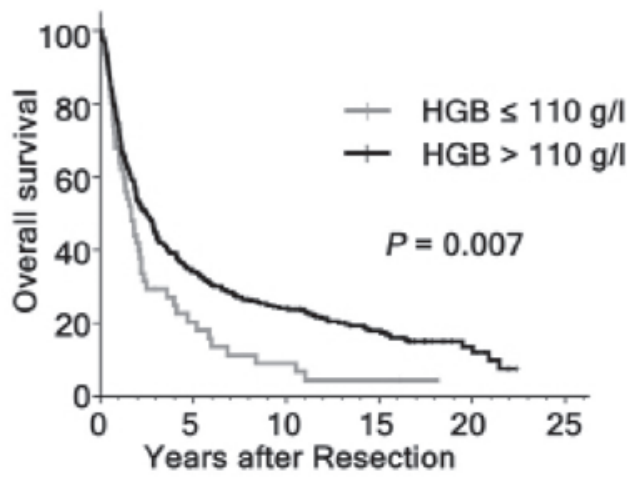

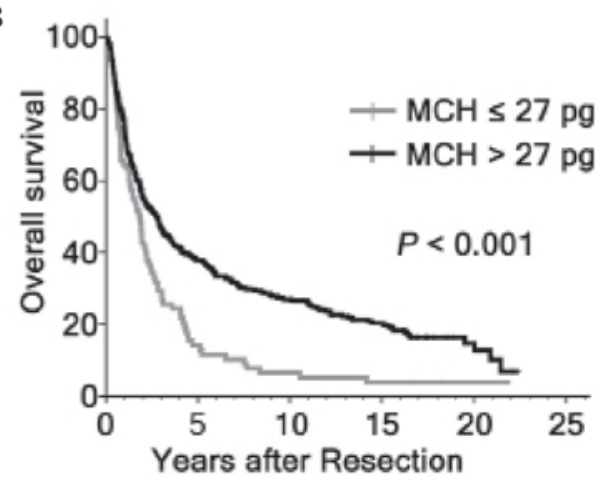

Figure 1. Overall survival assessed by Kaplan-Meier analysis in the entire cohort of patients with hepatocellular carcinoma, according to the levels of (A) HGB and (B) MCH. HGB, hemoglobin; MCH, mean corpuscular hemoglobin.

of HCC by the identical surgical team at the Department of Hepatobiliary Oncology, Sun Yat-Sen University Cancer Center (Guangdong, China). The diagnosis of HCC and underlying liver disease was confirmed in all patients by histological examination. Of these 445 cases, 399 had complete clinicopathological and follow-up data, however, had not received any preoperative treatments, including trans-hepatic arterial chemoembolization, radiotherapy or chemotherapy. The clinicopathological variables are shown in Table I. All blood samples were obtained 3 days prior to the operation. Tumor size was based on gross examination, as documented in the operation records, hepatitis B history was defined as a history with positive serum hepatitis B surface antigen (HBsAg), tumor encapsulation was defined that presence of a clear fibrous sheath around the tumor at gross inspection, tumor differentiation was based on the Edmondson-Steiner classification, and tumor number and macroscopic venous invasion were determined by the surgeon at the time of resection. The tumors were pathologically staged using the $7^{\text {th }}$ edition of the American Joint Committee on Cancer staging system (19). All recruited patients provided written informed consent prior to examination and treatment. The study protocol was approved by the Ethics Committee of Sun Yat-Sen University Cancer Center and conformed to the ethical guidelines of the Helsinki Declaration.

Tumor-associated anemia was defined as a HGB $\leq 110 \mathrm{~g} / \mathrm{l}$ without acute blood loss (20). $\mathrm{MCH} \leq 27 \mathrm{pg}$ (normal range, 27-32 pg) was used, since the decreased preoperative $\mathrm{MCH}$ level reflected low quantities of HGB per red blood cell.

Follow-up. Postoperative mortality was defined as all mortalities within 30 days of surgery or during the same hospital stay following liver resection. Following discharge, all patients were followed up regularly at the outpatient clinic, more that once every 3 months in the first year and every 3-6 months thereafter. The follow-up included a clinical examination, liver function tests, serum $\alpha$-fetoprotein (AFP) level, chest X-ray and abdomen ultrasonography. Computed tomography and/or magnetic resonance imaging were performed when intrahepatic recurrence or distant metastasis were suspected. The present study was censored on July $30^{\text {th }} 2011$. The median follow-up was 26 months (range, 1-269 months).
Statistical analysis. Descriptive statistics are expressed as the mean \pm standard deviation. The Chi-square test or Fisher's exact test, where appropriate, were used for univariate comparisons. The postoperative mortality was included when calculating the OS, using the Kaplan-Meier method. Cox's proportional hazard model was used for univariate and multivariate analyses of prognostic factors. $\mathrm{P}<0.05$ was considered to indicate a statistically significant difference. All statistical analyses were performed using SPSS statistical software package version 16.0 (SPSS, Inc., Chicago, IL, USA).

\section{Results}

Correlations of clinicopathological variables with $H G B$ and $\mathrm{MCH}$. The mean serum levels of HGB and $\mathrm{MCH}$ were $137.40 \pm 20.53 \mathrm{~g} / \mathrm{l}$ and $30.31 \pm 5.30 \mathrm{pg}$, respectively. These two continuous variables were positively associated with each other ( $\mathrm{r}=0.296, \mathrm{P}<0.001$; Data not shown). However, when they were dichotomized, according to the corresponding cut-off points, certain patients possessed high HGB and contrarily low MCH $(\mathrm{n}=49)$. As shown in Table I, $51(12.8 \%)$ patients had preoperative HGB $\leq 110 \mathrm{~g} / 1$. Low HGB level was only associated with female patients $(\mathrm{P}=0.029)$ and low $\mathrm{MCH}$ level was associated with female patients $(\mathrm{P}=0.011)$ and incomplete encapsulation $(\mathrm{P}=0.021)$.

Long-term outcome for patients with HCC following hepatic resection. A total of 327 mortalities were recorded until the final follow-up, of which six were hospital mortalities within 30 days of surgery. The majority of the remaining mortalities were due to tumor recurrence. A total of 74 patients in the cohort survived $>10$ years. The OS rates following hepatectomy at 5, 10 and 15 years were 32.5, 21.9 and $16.3 \%$ in the whole group, respectively. Variables, which may affect the OS of patients with HCC in this study were subjected to univariable and multivariable Cox regression analysis. Univariate analysis revealed that $\mathrm{HBsAg}(\mathrm{P}=0.024)$, tumor size $(\mathrm{P}<0.001)$, tumor encapsulation $(\mathrm{P}=0.002)$, tumor number $(\mathrm{P}<0.001)$, vascular invasion $(\mathrm{P}<0.001)$, tumor differentiation $(\mathrm{P}=0.031)$, tumor node metastasis $(\mathrm{TNM})$ stage $(\mathrm{P}<0.001)$, GGT $(\mathrm{P}<0.001)$, AFP $(\mathrm{P}=0.036)$, HGB $(\mathrm{P}=0.007)$ and $\mathrm{MCH}$ $(\mathrm{P}<0.001)$ levels were all significantly associated with the OS (Fig. 1; Table II). As the TNM stage was associated with 
Table II. Prognostic factors of OS in 399 patients with HCC.

\begin{tabular}{|c|c|c|c|c|c|c|}
\hline \multirow[b]{2}{*}{ Variable } & \multicolumn{3}{|c|}{ Univariate } & \multicolumn{3}{|c|}{ Multivariate } \\
\hline & HR & $95 \%$ CI & P-value & HR & $95 \%$ CI & P-value \\
\hline $\begin{array}{l}\text { Age, years } \\
>48 \text { vs. } \leq 48\end{array}$ & 0.932 & $0.750-1.758$ & 0.525 & & & \\
\hline $\begin{array}{l}\text { Gender } \\
\text { Male vs. female }\end{array}$ & 1.273 & $0.874-1.853$ & 0.208 & & & \\
\hline $\begin{array}{l}\text { HBsAg } \\
\text { Positive vs. negative }\end{array}$ & 1.382 & $1.043-1.830$ & 0.024 & 1.369 & $1.023-1.832$ & 0.035 \\
\hline $\begin{array}{l}\text { Cirrhosis } \\
\text { Yes vs. no }\end{array}$ & 1.100 & $0.843-1.435$ & 0.484 & & & \\
\hline $\begin{array}{l}\text { Tumor size, } \mathrm{cm} \\
\geq 10 \text { vs. }<10\end{array}$ & 1.699 & $1.347-2.143$ & $<0.001$ & 1.679 & $1.310-2.152$ & $<0.001$ \\
\hline $\begin{array}{l}\text { Tumor encapsulation } \\
\text { None vs. complete }\end{array}$ & 1.412 & $1.136-1.756$ & 0.002 & 1.138 & $0.899-1.441$ & 0.283 \\
\hline $\begin{array}{l}\text { Tumor no. } \\
\text { Multiple vs. solitary }\end{array}$ & 1.599 & $1.275-2.006$ & $<0.001$ & 1.123 & $0.872-1.448$ & 0.369 \\
\hline $\begin{array}{l}\text { Vascular invasion } \\
\text { Present vs. absent }\end{array}$ & 2.051 & $1.548-2.718$ & $<0.001$ & 1.758 & $1.305-2.367$ & $<0.001$ \\
\hline $\begin{array}{l}\text { Differentiation } \\
\text { III-IV vs. I-II }\end{array}$ & 1.298 & $1.024-1.645$ & 0.031 & 1.245 & $0.973-1.594$ & 0.082 \\
\hline $\begin{array}{l}\text { TNM stage } \\
\text { II-III vs. I }\end{array}$ & 1.678 & $1.346-2.091$ & $<0.001$ & & & \\
\hline $\begin{array}{l}\text { AFP, } \mu \mathrm{g} / 1 \\
>25 \text { vs. } \leq 25\end{array}$ & 1.284 & $1.107-1.622$ & 0.036 & 1.191 & $0.935-1.516$ & 0.157 \\
\hline $\begin{array}{l}\text { GGT, U/1 } \\
>50 \text { vs. } \leq 50\end{array}$ & 1.631 & $1.312-2.028$ & $<0.001$ & 1.486 & $1.184-1.866$ & 0.001 \\
\hline $\begin{array}{l}\text { HGB, g/l } \\
\leq 110 \text { vs. }>110\end{array}$ & 1.183 & $0.905-1.546$ & 0.007 & 1.205 & $0.861-1.686$ & 0.278 \\
\hline $\begin{array}{l}\text { MCH, pg } \\
\leq 27 \text { vs. }>27\end{array}$ & 1.737 & $1.346-2.242$ & $<0.001$ & 1.845 & $1.393-2.445$ & $<0.001$ \\
\hline
\end{tabular}

OS, overall survival; HCC, hepatocellular carcinoma; HR, hazard ratio; CI, confidence interval; HBsAg, hepatitis B surface antigen; TNM, tumor-node-metastasis; AFP, $\alpha$-fetoprotein; GGT, $\gamma$-glutamyl transpeptidase; HGB, hemoglobin; MCH, mean corpuscular hemoglobin.

several clinical indexes, including tumor size, tumor number and vascular invasion, the TNM stage was not entered into the multivariate Cox proportional hazards analysis with these indexes to avoid potential bias. In multivariate models, tumor size $(\mathrm{P}<0.001)$, vascular invasion $(\mathrm{P}<0.001)$, GGT $(\mathrm{P}=0.001)$, HBsAg $(\mathrm{P}=0.035)$ and $\mathrm{MCH}$ level $(\mathrm{P}<0.001)$ were revealed to be independently significant factors of OS (Table II).

Subanalysis of patients with large tumor size. Although previous studies have shown that hepatic resection is a safe modality for $\mathrm{HCC}>10 \mathrm{~cm}$, the efficacy of surgical resection for large HCC remained controversial for high risk of recurrence. In the present study, the patients with large $\mathrm{HCC}$ were associated with non-cirrhotic $(\mathrm{P}=0.012)$, absence of tumor encapsulation $(\mathrm{P}=0.025)$, multiple tumor number $(\mathrm{P}=0.001)$, presence of vascular invasion $(\mathrm{P}=0.003)$ and high TNM

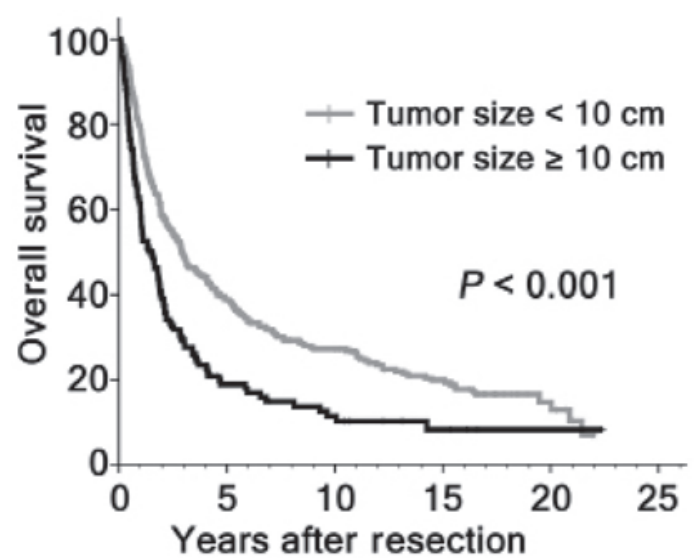

Figure 2. Overall survival, as assessed by Kaplan-Meier analysis in the entire cohort of patients with hepatocellular carcinoma. This analysis was performed, according to tumor size. 
Table III. Cinicopathalogical variables in patients with $\mathrm{HCC}>10 \mathrm{~cm}$ and in patients with smaller tumors.

\begin{tabular}{|c|c|c|c|c|}
\hline Variable & $\begin{array}{c}\text { No. } \\
\text { cases }\end{array}$ & $\begin{array}{c}\mathrm{HCC}<10 \mathrm{~cm} \\
\mathrm{n}(\%) \\
(\mathrm{n}=272)\end{array}$ & $\begin{array}{c}\mathrm{HCC} \geq 10 \mathrm{~cm} \\
\mathrm{n}(\%) \\
(\mathrm{n}=127)\end{array}$ & P-value \\
\hline \multicolumn{5}{|l|}{ Age, years } \\
\hline$\leq 48$ & 207 & $237(50.4)$ & $70(55.1)$ & \multirow{2}{*}{0.376} \\
\hline$>48$ & 192 & 135 (49.6) & $57(44.9)$ & \\
\hline \multicolumn{5}{|l|}{ Gender } \\
\hline Female & 43 & $30(11.0)$ & $13(10.2)$ & \multirow{2}{*}{0.812} \\
\hline Male & 356 & $242(89.0)$ & $114(89.8)$ & \\
\hline \multicolumn{5}{|l|}{ HBsAg } \\
\hline Negative & 80 & $55(20.2)$ & $25(19.7)$ & \multirow{2}{*}{0.901} \\
\hline Positive & 319 & $217(79.8)$ & $102(80.3)$ & \\
\hline \multicolumn{5}{|l|}{ Cirrhosis } \\
\hline No & 86 & $49(18.0)$ & $37(29.1)$ & \multirow{2}{*}{0.012} \\
\hline Yes & 313 & $223(82.0)$ & $90(70.9)$ & \\
\hline \multicolumn{5}{|l|}{ Tumor encapsulation } \\
\hline Complete & 193 & $142(52.2)$ & $51(40.2)$ & \multirow{2}{*}{0.025} \\
\hline None & 206 & $130(47.8)$ & $76(59.8)$ & \\
\hline \multicolumn{5}{|l|}{ Tumor no. } \\
\hline Solitary & 259 & $191(70.2)$ & $68(53.5)$ & \multirow{2}{*}{0.001} \\
\hline Multiple & 140 & $81(29.8)$ & $59(46.5)$ & \\
\hline \multicolumn{5}{|l|}{ Vascular invasion } \\
\hline Absent & 326 & $233(85.7)$ & $93(73.2)$ & \multirow{2}{*}{0.003} \\
\hline Present & 73 & $39(14.3)$ & $34(26.8)$ & \\
\hline \multicolumn{5}{|l|}{ Differentiation } \\
\hline I-II & 285 & $194(71.3)$ & $91(71.7)$ & \multirow{2}{*}{0.946} \\
\hline III-IV & 114 & $78(28.7)$ & $36(28.3)$ & \\
\hline \multicolumn{5}{|l|}{ TNM stage } \\
\hline I & 225 & $170(62.5)$ & $55(43.3)$ & \multirow{2}{*}{$<0.001$} \\
\hline II-III & 174 & $102(37.5)$ & $72(56.7)$ & \\
\hline \multicolumn{5}{|l|}{$\mathrm{AFP}, \mu \mathrm{g} / 1$} \\
\hline$\leq 25$ & 127 & $88(32.4)$ & $39(30.7)$ & \multirow{2}{*}{0.743} \\
\hline$>25$ & 272 & $184(67.6)$ & $38(69.3)$ & \\
\hline Hospital mortality & 6 & $2(0.7)$ & $4(3.1)$ & 0.084 \\
\hline
\end{tabular}

HCC, hepatocellular carcinoma; HBsAg, hepatitis B surface antigen; TNM, tumor-node-metastasis; AFP, $\alpha$-fetoprotein.

stage $(\mathrm{P}<0.001$; Table III). In addition, tumors $\geq 10 \mathrm{~cm}$ had a tendency of higher postoperative mortality compared with patients with smaller HCC (3.1, vs. 0.7\%; P=0.084; Table III). The OS rates at 5, 10 and 15 years for patients with large HCC were significantly lower compared with those with smaller HCC (18.3, vs. 38.9, 9.4, vs. 27.4 and 7.1, vs. 20.1\%, respectively; $\mathrm{P}<0.001$; Fig. 2). However, 18/127 (14.2\%) patients with large HCC survived $>5$ years following hepatic resection. A natural question arose as to whether selected cases with larger HCC had favorable survival. Therefore, the present study further investigated the prognostic significance of HGB, $\mathrm{MCH}$ and other clinicopathological variables on OS among the 127 patients with large HCC. By univariate analysis, HGB level was not associated with OS $(\mathrm{P}=0.889)$, while tumor encapsulation $(\mathrm{P}=0.001)$, vascular invasion $(\mathrm{P}<0.001)$, tumor differentiation $(\mathrm{P}<0.001)$ and $\mathrm{MCH}$ level $(\mathrm{P}=0.004)$ were significant prognostic factors for OS (Fig. 3; Table IV). On multivariate analysis, vascular invasion $(\mathrm{P}<0.001)$, tumor differentiation $(\mathrm{P}<0.001)$ and $\mathrm{MCH}$ level $(\mathrm{P}=0.001)$ were identified as independent prognostic indicators for OS (Table IV).

\section{Discussion}

It has been previously reported that anemia was prevalent in certain patients with malignant disease (12), however, few studies reported the prevalence of anemia in HCC. Qiu et al (16) revealed that the percentage of pretreatment anemia in the HCC group was $7.0 \%$, which was $<12.8 \%$ of the 
Table IV. Prognostic factors of OS in patients with $\mathrm{HCC}>10 \mathrm{~cm}$.

\begin{tabular}{|c|c|c|c|c|c|c|}
\hline \multirow[b]{2}{*}{ Variable } & \multicolumn{3}{|c|}{ Univariate } & \multicolumn{3}{|c|}{ Multivariate } \\
\hline & HR & $95 \% \mathrm{CI}$ & P-value & HR & $95 \% \mathrm{CI}$ & P-value \\
\hline \multicolumn{7}{|l|}{ Age, years } \\
\hline$>48$ vs. $\leq 48$ & 0.770 & $0.527-1.125$ & 0.175 & & & \\
\hline \multicolumn{7}{|l|}{ Gender } \\
\hline Male vs. female & 1.829 & $0.889-3.761$ & 0.096 & & & \\
\hline \multicolumn{7}{|l|}{$\mathrm{HBsAg}$} \\
\hline Positive vs. negative & 1.530 & $0.932-2.513$ & 0.090 & & & \\
\hline \multicolumn{7}{|l|}{ Cirrhosis } \\
\hline Yes vs. no & 1.349 & $0.887-2.052$ & 0.161 & & & \\
\hline \multicolumn{7}{|l|}{ Tumor encapsulation } \\
\hline None vs. complete & 1.887 & $1.274-2.795$ & 0.001 & 1.276 & $0.824-1.976$ & 0.274 \\
\hline \multicolumn{6}{|l|}{ Tumor no. } & \\
\hline \multicolumn{7}{|l|}{ Vascular invasion } \\
\hline Present vs. absent & 2.768 & $1.777-4.310$ & $<0.001$ & 2.363 & $1.486-3.759$ & $<0.001$ \\
\hline \multicolumn{7}{|l|}{ Differentiation } \\
\hline III-IV vs. I-II & 2.194 & $1.453-3.312$ & $<0.001$ & 2.179 & $1.406-3.375$ & $<0.001$ \\
\hline \multicolumn{7}{|l|}{ TNM stage } \\
\hline II-III vs. I & 1.579 & $1.074-2.323$ & 0.019 & & & \\
\hline \multicolumn{7}{|l|}{$\mathrm{AFP}, \mu \mathrm{g} / \mathrm{l}$} \\
\hline$>25$ vs. $\leq 25$ & 1.493 & $0.989-2.255$ & 0.055 & & & \\
\hline \multicolumn{7}{|l|}{ GGT, U/1 } \\
\hline$>50$ vs. $\leq 50$ & 1.469 & $0.987-2.186$ & 0.056 & & & \\
\hline \multicolumn{7}{|l|}{ HGB, g/l } \\
\hline$\leq 110$ vs. $>110$ & 0.961 & $0.548-1.686$ & 0.889 & & & \\
\hline \multicolumn{7}{|l|}{$\mathrm{MCH}, \mathrm{pg}$} \\
\hline$\leq 27$ vs. $>27$ & 1.931 & $1.224-3.049$ & 0.004 & 2.222 & $1.361-3.636$ & 0.001 \\
\hline
\end{tabular}

OS, overall survival; HCC, hepatocellular carcinoma; HR, hazard ratio; CI, confidence interval; HBsAg, hepatitis B surface antigen; TNM, tumor-node-metastasis; AFP, $\alpha$-fetoprotein; GGT, $\gamma$-glutamyl transpeptidase; HGB, hemoglobin; MCH, mean corpuscular hemoglobin.
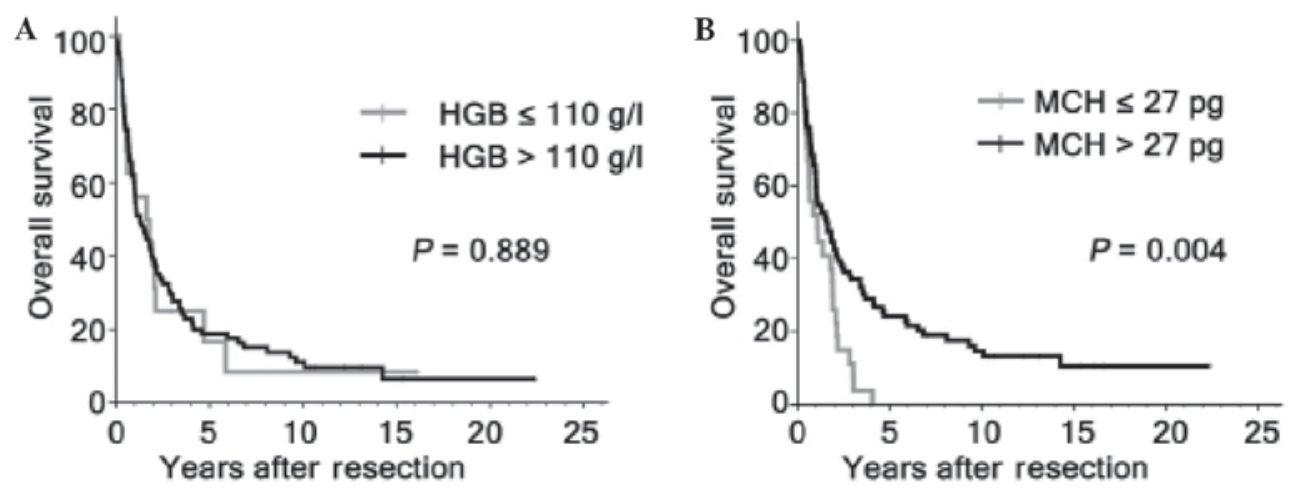

Figure 3. Overall survival assessed by Kaplan-Meier analysis in the subgroup of patients with hepatocellular carcinoma with large tumor size, according to the levels of (A) HGB and (B) MCH. HGB, hemoglobin; MCH, mean corpuscular hemoglobin.

present study. This difference may be due to study population selection bias.
The prevalence of anemia among patients with HCC may be associated with a number of reasons. The pathogenesis of 
cancer-associated anemia, including nutritional deficiency, hemolysis, blood loss and infiltration of the bone marrow by tumor cells was postulated to be one of the common causes (21). Similarly, chronic liver injury can result in anemia in patients with HCC (22). A previous study showed that downregulation of iron-regulatory genes, including hepcidin, ceruloplasmin, transferrin and transferrin receptor, disturbed systemic iron balance and contributed to anemia in patients with HCC (23). Disordered iron homeostasis is considered to be a co-factor in the onset and progression of almost all liver diseases, including the development of HCC (24). In the present study, it was revealed that one of the iron status markers, $\mathrm{MCH}$, was reduced in $12.8 \%$ of the patients with $\mathrm{HCC}$ in the entire cohort. The positive correlation of $\mathrm{MCH}$ and $\mathrm{HGB}$ indicated that anemia was partially caused by iron deficiency.

In numerous previous studies, HGB levels, either prior to or during anticancer treatment, have been shown to have an impact on survival $(15,25)$. Cordella et al (26) demonstrated that a low level of HGB was an indicator for lymph node metastasis and poor survival of oral squamous cell carcinoma. Two independent studies demonstrated that low HGB was a significant risk factor for patients with non-small cell lung cancer TNM stage I $(27,28)$. Qiu et al (16) previously showed that anemia was an independent prognostic factor in patients with HCC. However, no previous study focused on the correlation of $\mathrm{MCH}$ with survival in patients with cancer. In the present study, it was revealed that both preoperative HGB and $\mathrm{MCH}$ were correlated with gender. Furthermore, patients with low levels of $\mathrm{MCH}$ were more prone to have absence of tumor encapsulation. Although $\mathrm{HGB}$ and $\mathrm{MCH}$ were not observed to be widely associated with tumor-associated factors, the outcome in patients with low levels of $\mathrm{HGB}$ or $\mathrm{MCH}$ was poor overall on univariate analysis. Therefore, $\mathrm{HGB}$ and $\mathrm{MCH}$ appeared to be reliable prognostic biomarkers. However, multivariate analysis using the Cox proportional hazard model demonstrated that $\mathrm{MCH}$, however, not HGB was associated with poor survival following consideration of other prognostic factors. Multivariate analysis excluding HGB level is probably due to the correlation between the presence of anemia and iron deficiency. In general, $\mathrm{MCH}$ is one of the hematological indicators of iron deficiency $(29,30)$. Several previous studies have shown that microcytic hypochromic anemia is associated with iron overload, particularly in the liver $(31,32)$. In fact, iron overload is considered to be a co-factor in the onset and progression of HCC (24). Taken together, iron overload may explain, at least in part, poorer prognosis of HCC patients with low levels of $\mathrm{MCH}$.

In the entire cohort, 127 (31.8\%) patients with HCC met the tumor size $\geq 10 \mathrm{~cm}$. As previously reported (33), the present study revealed that large HCCs were more aggressive compared with smaller HCCs. Additionally, extremely poor outcome following resection for large HCC was clear. It appeared that resection for large HCC was not a good selection for treatment. However, increasing evidence indicated that hepatic resection performed on carefully selected patients was safe and effective for HCC patients with large tumor size (2). Similarly, hospital mortality between the two groups was comparable in the present study, which suggested that hepatic resection for large HCC was safe. With the improvements in surgical techniques and peri-operative care, hepatic resection for large HCC provided an improved long-term survival compared with transcatheter arterial chemoembolization or other therapies (34). However, surgical resection had excellent outcomes only in carefully selected patients with large tumor size. In trying to select those patients with large HCCs, which may be best served by resection, several previous studies had defined the prognostic factors for HCC with large tumor types (35). A previous review summed up the risk factors influencing the survival of large $\mathrm{HCC}$ under resection (2), and the risk factor with the highest prevalence was vascular invasion. Two previous reports revealed that poor tumor differentiation indicates inferior OS of large $\operatorname{HCC}(36,37)$. In the present study, vascular invasion and poor tumor differentiation was able to predict poor OS in HCC patients with large tumors. Similarly, when we observed HCC patients with large tumors, $\mathrm{MCH}$ significantly predicted OS. Together, the present data indicated that $\mathrm{MCH}$, which are easily obtained, may be an important consideration when selecting $\mathrm{HCC}$ with large tumors for hepatectomy.

One of the major limitations of the present study was that the quantity of iron deposition in the liver was not determined. Whether low MCH level was associated with iron overload in the liver remains to be elucidated. Therefore, the present study hypothesized that the underlying pathophysiology in HCC patients with low MCH level warrants further investigation. Retrospective design, which has the associated issues of potential selection bias, was another limitation. In this case, consecutive patient sampling was used to reduce patient selection bias. Notably, the present results require further confirmation by prospective investigations in multicenter clinical trials.

In conclusion, the present study demonstrated that $\mathrm{MCH}$ level effectively classified patients with HCC under liver resection into groups of poor and improved outcomes, thereby adding novel prognostic value to traditional clinicopathological risk factors. Additionally, selection based on $\mathrm{MCH}$ level may be modified to identify patients with large HCC who are most likely benefit from resection.

\section{Acknowledgements}

The present study was supported by grants from the National Natural Science Foundation of China (no. 81372571) and the Guangdong Department of Science and Technology Translational Medicine Center (no. 2011A080300002).

\section{References}

1. Jemal A, Bray F, Center MM, Ferlay J, Ward E and Forman D: Global cancer statistics. CA Cancer J Clin 61: 69-90, 2011.

2. Tsoulfas G, Mekras A, Agorastou P and Kiskinis D: Surgical treatment for large hepatocellular carcinoma: Does size matter? ANZ J Surg 82: 510-517, 2012.

3. Tung-Ping Poon R, Fan ST and Wong J: Risk factors, prevention and management of postoperative recurrence after resection of hepatocellular carcinoma. Ann Surg 232: 10-24, 2000.

4. Forner A, Llovet JM and Bruix J: Hepatocellular carcinoma. Lancet 379: 1245-1255, 2012.

5. Villanueva A, Minguez B, Forner A, Reig M and Llovet JM: Hepatocellular carcinoma: Novel molecular approaches for diagnosis, prognosis and therapy. Annu Rev Med 61: 317-328, 2010.

6. Villanueva A, Hoshida Y, Toffanin S, et al: New strategies in hepatocellular carcinoma: Genomic prognostic markers. Clin Cancer Res 16: 4688-4694, 2010. 
7. Ju MJ, Qiu SJ, Fan J, et al: Preoperative serum gamma-glutamy transferase to alanine aminotransferase ratio is a convenient prognostic marker for Child-Pugh A hepatocellular carcinoma after operation. J Gastroenterol 44: 635-642, 2009.

8. Sasaki A, Iwashita Y, Shibata K, et al: Prognostic value of preoperative peripheral blood monocyte count in patients with hepatocellular carcinoma. Surgery 139: 755-764, 2006.

9. Amano H, Tashiro H, Oshita A, et al: Significance of platelet count in the outcomes of hepatectomized patients with hepatocellular carcinoma exceeding the Milan criteria. J Gastrointest Surg 15: 1173-1181, 2011.

10. Mano Y, Shirabe K, Yamashita Y, et al: Preoperative neutrophil-to-lymphocyte ratio is a predictor of survival after hepatectomy for hepatocellular carcinoma: A retrospective analysis. Ann Surg 258: 301-305, 2013.

11. Boogaerts M, Mittelman M and Vaupel P: Beyond anaemia management: Evolving role of erythropoietin therapy in neurological disorders, multiple myeloma and tumour hypoxia models. Oncology 69 (Suppl 2): S22-S30, 2005.

12. Caro JJ, Salas M, Ward A and Goss G: Anemia as an independent prognostic factor for survival in patients with cancer: A systemic, quantitative review. Cancer 91: 2214-2221, 2001.

13. Holzner B, Kemmler G, Greil R, et al: The impact of hemoglobin levels on fatigue and quality of life in cancer patients. Ann Oncol 13: 965-973, 2002.

14. Van Belle SJ and Cocquyt V: Impact of haemoglobin levels on the outcome of cancers treated with chemotherapy. Crit Rev Oncol Hematol 47: 1-11, 2003.

15. Kim JH, Lee JM, Ryu KS, et al: The prognostic impact of duration of anemia during chemotherapy in advanced epithelial ovarian cancer. Oncologist 16: 1154-1161, 2011.

16. Qiu MZ, Xu RH, Ruan DY, et al: Incidence of anemia, leukocytosis and thrombocytosis in patients with solid tumors in China. Tumour Biol 31: 633-641, 2010.

17. Wu XN, Su D, Wang L and Yu FL: Roles of the hepcidin-ferroportin axis and iron in cancer. Eur J Cancer Prev 23: 122-133, 2014.

18. Heath JL, Weiss JM, Lavau CP and Wechsler DS: Iron deprivation in cancer--potential therapeutic implications. Nutrients 5 : 2836-2859, 2013

19. Chun YH, Kim SU, Park JY, Kim do Y, Han KH, Chon CY, Kim BK, Choi GH, Kim KS, Choi JS and Ahn SH: Prognostic value of the 7th edition of the AJCC staging system as a clinical staging system in patients with hepatocellular carcinoma. Eur J Cancer 47: 2568-2575, 2011

20. Chen MH, Chang PM, Chen PM, et al: Prognostic significance of a pretreatment hematologic profile in patients with head and neck cancer. J Cancer Res Clin Oncol 135: 1783-1790, 2009.

21. Aapro M, Österborg A, Gascón P, Ludwig H and Beguin Y: Prevalence and management of cancer-related anaemia, iron deficiency and the specific role of i.v. iron. Ann Oncol 23: 1954-1962, 2012.
22. Intragumtornchai T, Rojnukkarin $\mathrm{P}$, Swasdikul D, et al: Anemias in Thai patients with cirrhosis. Int J Hematol 65: 365-373, 1997.

23. Tseng HH, Chang JG, Hwang YH, et al: Expression of hepcidin and other iron-regulatory genes in human hepatocellular carcinoma and its clinical implications. J Cancer Res Clin Oncol 135: 1413-1420, 2009.

24. Deugnier Y and Turlin B: Pathology of hepatic iron overload. Semin Liver Dis 31: 260-271, 2011.

25. Reichel O, Panzer M, Wimmer C, et al: Prognostic implications of hemoglobin levels before and after surgery as well as before and after radiochemotherapy for head and neck tumors. Eur Arch Otorhinolaryngol 260: 248-253, 2003.

26. Cordella C, Luebbers HT, Rivelli V, Grätz KW and Kruse AL: An evaluation of the preoperative hemoglobin level as a prognostic factor for oral squamous cell carcinoma. Head Neck Oncol 3: 35, 2011.

27. Tomita M, Shimizu T, Hara M, Ayabe T and Onitsuka T: Impact of preoperative hemoglobin level on survival of non-small cell lung cancer patients. Anticancer Res 28 (3B): 1947-1950, 2008.

28. Yovino S, Kwok Y, Krasna M, et al: An association between preoperative anemia and decreased survival in early-stage non-small-cell lung cancer patients treated with surgery alone. Int J Radiat Oncol Biol Phys 62: 1438-1443, 2005.

29. Juncà J, Fernández-Avilés F, Oriol $\mathrm{A}$, et al: The usefulness of the serum transferrin receptor in detecting iron deficiency in the anemia of chronic disorders. Haematologica 83: 676-680, 1998.

30. Alquaiz JM, Abdulghani HM, Khawaja RA and Shaffi-Ahamed S: Accuracy of various iron parameters in the prediction of iron deficiency anemia among healthy women of child bearing age, Saudi Arabia. Iran Red Crescent Med J 14: 397-401, 2012.

31. Iolascon A, De Falco L and Beaumont C: Molecular basis of inherited microcytic anemia due to defects in iron acquisition or heme synthesis. Haematologica 94: 395-408, 2009.

32. Batts KP: Iron overload syndromes and the liver. Mod Pathol 20 (Suppl 1): S31-S39, 2007.

33. Truant S, Boleslawski E, Duhamel A, et al: Tumor size of hepatocellular carcinoma in noncirrhotic liver: A controversial predictive factor for outcome after resection. Eur J Surg Oncol 38: 1189-1196, 2012

34. Zhong JH, Ke Y, Gong WF, et al: Hepatic resection associated with good survival for selected patients with intermediate and advanced-stage hepatocellular carcinoma. Ann Surg 260: 329-340, 2014

35. Shah SA, Wei AC, Cleary SP, Yang I, McGilvray ID, Gallinger S, Grant DR and Greig PD: Prognosis and results after resection of very large $(>$ or $=10 \mathrm{~cm})$ hepatocellular carcinoma. J Gastrointest Surg 11: 589-595, 2007.

36. Mok KT, Wang BW, Lo GH, et al: Multimodality management of hepatocellular carcinoma larger than $10 \mathrm{~cm}$. J Am Coll Surg 197: 730-738, 2003

37. Shrager B, Jibara GA, Tabrizian P, et al: Resection of large hepatocellular carcinoma $(\geq 10 \mathrm{~cm})$ : A unique western perspective. J Surg Oncol 107: 111-117, 2013. 